\section{Manage military land for the environment}

A refocus on managing military training grounds for their value to the environment as well as to the armed forces would drastically increase the global terrestrial 'protected area' at minimal cost (see J. E. M. Watson et al. Nature 515, 67-73; 2014).

We estimate that training areas total at least 50 million hectares, with the actual figure probably closer to 300 million hectares (R. Zentelis and D. Lindenmayer Conserv. Lett., in the press). These areas encompass all major global ecosystems, including those poorly represented within formal reserve systems. In the Western world, at least, their management is already funded through military expenditure.

Many examples highlight the value of such areas. They support the majority of Germany's wolf packs, and in Australia they contain some of the best remaining threatened coastal heathland. Regardless of one's view of the military, the armed forces manage a huge area of land that, until now, has not been recognized as an important funded conservation resource.

Rick Zentelis, David

Lindenmayer Australian National University, Canberra, Australia. rick.zentelis@anu.edu.au

\section{Europe is failing young researchers}

We are young European researchers and participants in science-policy initiatives who feel strongly that the European Research Area (ERA) faces many challenges.

The absence of a fully inclusive and self-sufficient ERA still affects research institutions locally. Regional funding remains too sparse and fragmented. As well as a dearth of sustainable career opportunities, there is widespread cronyism, and many administrative and research structures are obsolete.
We need more transparency and objectivity in funding, promotions and hiring practices. Such reforms would cost relatively little and might even make some funding cuts unnecessary.

The responsibility for improvement lies not only with the European governing bodies, but also with member states and regions. These are issues on which the undersigned all agree - we are members of the COST SciGeneration Network, the Young Academy of Europe, the Global Young Academy and EURAXESS Voice of the Researchers. Thomas Schäfer* Polymat, University of the Basque Country, Donostia-San Sebastián; and Ikerbasque, Bilbao, Spain. thomas.schafer@ehu.es ${ }^{*}$ On behalf of 15 correspondents (see go.nature.com/ab6jtb for full list).

\section{Biodiversity reports need author rules}

Two representatives from the agrochemical industry are among 40 authors of a fasttrack assessment of pollinators by the Intergovernmental Platform on Biodiversity and Ecosystem Services (IPBES; see go.nature.com/q81112). In our view, to support the credibility of assessment results, the IPBES needs a policy requiring authors to declare all funding sources, positions held and other potential conflicts of interest.

It is unclear how the IPBES deals with conflicts of interest. Their second plenary meeting last December postponed a decision on the matter. Authors are nominated by IPBES member states and other stakeholders to "reflect the range of scientific, technical and socio-economic views and expertise; geographical representation ...; the diversity of knowledge systems ...; and gender balance". But the IPBES has no explicit rules for nomination or selection.

IPBES assessments could lead to far-reaching policy interventions, with financial implications for industry sectors (for example, in mining after assessment of land degradation and restoration, or for transport after invasive-species assessment). Given the role of agrochemicals in pollinator decline (J. van der Sluijs et al. Environ. Sci. Pollut. Res. http://doi.org/xcx; 2014), it is our view that scientists funded by such corporations should not be lead authors or coordinating lead authors on such assessments.

We also suggest that the IPBES publishes the names of all nominated authors, along with their nominators and justification for their appointment.

Axel Hochkirch Trier University, Germany.

Philip J. K. McGowan Newcastle University, UK.

Jeroen van der Sluijs University

of Bergen, Norway.

hochkirch@uni-trier.de

\section{Engaged cohort good for science}

As staff at the UK Avon

Longitudinal Study of Parents and Children (ALSPAC), we agree that participant involvement is crucial to the design of cohort studies (P. Lucas et al. Nature $\mathbf{5 1 4}, 567 ; 2014)$. We work with an advisory panel composed of a large and representative selection of original cohort participants.

The panel provides regular, thoughtful feedback and advice to ALSPAC researchers about datacollection exercises. It comments on proposals, the appropriateness of questions, communications materials and channels, research findings and the burden on participants. This helps to improve our study and makes the broader cohort more likely to engage in our research.

We also host focus groups and online discussion forums with all segments of our cohort - mothers, fathers, siblings and young parents - and use Facebook and Twitter. ALSPAC is cited as an example of best socialmedia practice in guidelines from the UK National Institute for
Health Research (see go.nature. com/txsxma).

We look for new ways to hear participants' views, on topics from our newsletters to a 2012 events programme (see Nature 484, 155-158; 2012). Devised by participants to mark their 21st birthdays, this included a science festival, a conference, parties for study children and parents, and a commemorative book.

Katarzyna Kordas, Dara O'Hare, Makaela Jacobs-Pearson University of Bristol, UK. kasia.kordas@bristol.ac.uk

\section{Several fields still need primates}

Eliminating the use of nonhuman primates in certain fields (see P. Bateson and C. I. Ragan

Nature 514, 567; 2014) has no bearing on their utility in neuropsychiatry and neurology.

The use of these animals, including genetically modified marmosets, is in our view essential for fundamental research into mental-health disorders. Similarities in the structure of higher-order cortical brain regions - which are dysregulated in disorders such as depression and schizophrenia - enable the most accurate and relevant mapping of the primate brain's functional organization.

A prominent example is the mapping of neural pathways in the rhesus monkey, which led to the discovery that deep brain stimulation can be an effective treatment for Parkinson's disease (see go.nature.com/28spre).

The US National Institute of Mental Health has recognized that such fundamental research should be applied to the understanding and treatment of neuropsychiatric disorders (Research Domain Criteria; see go.nature.com/or4keu), to identify discrete psychological deficits associated with specific neural pathways.

Angela Roberts, Trevor Robbins University of Cambridge, UK. acr4@cam.ac.uk 